\title{
Phosphoinositide Profile of the Mouse Retina
}

\author{
Stella Finkelstein ${ }^{1,+}{ }^{,}$, Sidney M. Gospe III ${ }^{1,+} \oplus$, Kai Schuhmann ${ }^{2}$, Andrej Shevchenko ${ }^{2}$, \\ Vadim Y. Arshavsky ${ }^{1,3}(\mathbb{D})$ and Ekaterina S. Lobanova $4,5, * \mathbb{D}$ \\ 1 Department of Ophthalmology, Duke University, Durham, NC 27710, USA; stella@duke.edu (S.F.); \\ sid.gospe@duke.edu (S.M.G.III); vadim.arshavsky@duke.edu (V.Y.A.) \\ 2 Max Planck Institute of Molecular Cell Biology and Genetics, 01307 Dresden, Germany; \\ schuhman@mpi-cbg.de (K.S.); shevchenko@mpi-cbg.de (A.S.) \\ 3 Department of Pharmacology and Cancer Biology, Duke University, Durham, NC 27710, USA \\ 4 Department of Ophthalmology, University of Florida, Gainesville, FL 32610, USA \\ 5 Department of Pharmacology and Therapeutics, University of Florida, Gainesville, FL 32610, USA \\ * Correspondence: elobanova@ufl.edu \\ + These authors contributed equally to this work.
}

Received: 7 April 2020; Accepted: 4 June 2020; Published: 7 June 2020

\begin{abstract}
Phosphoinositides are known to play multiple roles in eukaryotic cells. Although dysregulation of phosphoinositide metabolism in the retina has been reported to cause visual dysfunction in animal models and human patients, our understanding of the phosphoinositide composition of the retina is limited. Here, we report a characterization of the phosphoinositide profile of the mouse retina and an analysis of the subcellular localization of major phosphorylated phosphoinositide forms in light-sensitive photoreceptor neurons. Using chromatography of deacylated phosphatidylinositol headgroups, we established $\mathrm{PI}(4,5) \mathrm{P}_{2}$ and $\mathrm{PI}(4) \mathrm{P}$ as two major phosphorylated phosphoinositides in the retina. Using high-resolution mass spectrometry, we revealed 18:0/20:4 and 16:0/20:4 as major fatty-acyl chains of retinal phosphoinositides. Finally, analysis of fluorescent phosphoinositide sensors in rod photoreceptors demonstrated distinct subcellular distribution patterns of major phosphoinositides. The $\mathrm{PI}(4,5) \mathrm{P}_{2}$ reporter was enriched in the inner segments and synapses, but was barely detected in the light-sensitive outer segments. The PI(4)P reporter was mostly found in the outer and inner segments and the areas around nuclei, but to a lesser degree in the synaptic region. These findings provide support for future mechanistic studies defining the biological significance of major mono- $(\mathrm{PI}(4) \mathrm{P})$ and bisphosphate $\left(\mathrm{PI}(4,5) \mathrm{P}_{2}\right)$ phosphatidylinositols in photoreceptor biology and retinal health.
\end{abstract}

Keywords: retina; phosphatidylinositol phosphate; phosphatidylinositol bisphosphate; photoreceptor

\section{Introduction}

Phosphoinositide phospholipids are essential components of membranes in every cell. The parent phosphatidylinositol (PI) can be phosphorylated combinatorially on the inositol ring at the 3-, 4-, or 5- position(s). Levels of phosphorylated phosphatidylinositols are tightly controlled by the activities of specific phosphoinositide kinases and phosphatases. Individual forms of phosphorylated phosphoinositides serve as unique signals to engage a variety of phosphoinositide binding proteins, thus affecting diverse cellular processes, including protein transport, cell polarity, cytoskeletal organization, ion-channel function, and gene expression [1-4]. Dysregulation of phosphoinositide metabolism has been reported to result in retinal dysfunction in animal models and humans. For instance, zebrafish mutants deficient in SynJ1, a phosphoinositide phosphatase, demonstrate signs of disrupted transport of synaptic proteins and defects in autophagosomal and endosomal trafficking within photoreceptors [5,6]. The loss of PI-3 kinase Vps34 in mice leads to deficiencies 
in endosome recycling and aggressive degeneration of photoreceptors [7]. Genetic inactivation of the p110 $\alpha$-subunit of PI-3 kinase in cones similarly demonstrated the critical role of PI3K signaling in photoreceptor survival [8]. In humans, mutations in the phosphoinositide metabolizing enzyme INPP5E have been linked to progressive retinopathy in Joubert syndrome $[9,10]$, and abnormalities in phosphoinositide-binding proteins have been linked to photoreceptor degeneration in humans and mice [11-13]. The phosphoinositide binding proteins have been proposed to play a role in vesicular transport in rods [14,15]. Finally, several publications indicate that light regulates phosphoinositide metabolism in the retina (reviewed in $[16,17])$. However, the functional significance of this regulation is unknown, and the direction of light-induced phosphoinositide changes remains controversial.

Despite accumulating evidence that phosphoinositide signaling plays a critical role in many cellular functions, little is currently known about the phosphoinositide composition of the retina. Historically, phosphoinositides were studied in cell culture using radionuclide labeling approaches. However, the poor viability of the retina in vitro limits the utility of radiolabeling-based approaches in analyzing this tissue. Furthermore, these methods allow monitoring of phosphoinositide turnover, but cannot measure absolute phosphoinositide levels. Therefore, in this study, we took advantage of modern non-radiolabeling techniques to profile phosphorylated phosphoinositides of the mouse retina. Our study establishes $\mathrm{PI}(4) \mathrm{P}$ and $\mathrm{PI}(4,5) \mathrm{P}_{2}$ as major phosphorylated headgroups and 16:0/20:4 and 18:0/20:4 as dominant fatty acid species of retinal phosphatidylinositols. Furthermore, our analysis identifies distinct patterns of subcellular localization of these lipids within photoreceptors. These findings position $\mathrm{PI}(4) \mathrm{P}$ and $\mathrm{PI}(4,5) \mathrm{P}_{2}$ lipids as central players in future studies of phosphoinositide metabolism in photoreceptors.

\section{Materials and Methods}

\subsection{Animals}

All procedures conformed to the Association for Research in Vision and Ophthalmology Statement for the Use of Animals in Ophthalmic and Vision Research and were approved by the Institutional Animal Care and Use Committee of University of Florida (study \# 201709934, approved 9/20/2017). Wild type C57BL/6J mice were purchased from Jackson Laboratory (stock \# 000664) and housed under a $12 / 12 \mathrm{~h}$ dark/light cycle. Mice were maintained on a plant-based diet (Teklad global 18\% protein rodent diet \#2918, Envigo). For dark adaptation, mice were kept in a dark room for $12 \mathrm{~h}$. For light conditioning, dark-adapted mice with dilated pupils were exposed to a light intensity of 500 lux for one hour. Animals were euthanized with isoflurane, followed by decapitation after the animals were rendered non-responsive. For lipid analysis, retinas were carefully dissected from enucleated eyes under infrared (for dark adaptation experiments) or room light (for light adaptation experiments) in Ringer's solution, flash-frozen in liquid nitrogen, and stored at $-80^{\circ} \mathrm{C}$. For subcellular localization studies of phosphoinositide sensors, the retinal agarose sections were prepared as previously described $[18,19]$. Briefly, eyes were fixed overnight in $4 \%$ paraformaldehyde prepared in phosphate-buffered Saline (PBS), rinsed in PBS, and embedded in $4 \%$ low-melt agarose. 100- $\mu \mathrm{m}$ retinal sections were collected using a Leica vibratome (VT1200S), mounted on slides under coverslips with Fluoromount (Electron Microscopy Sciences), and analyzed with a Nikon A1 Spectral Confocal Microscope.

\subsection{Chemicals}

Chemicals and solvents of ACS (American Chemical Society) or LC-MS (Liquid Chromatography-Mass Spectrometry) grade were purchased from Sigma-Aldrich, and synthetic lipid standards were purchased from Avanti Polar Lipids.

\subsection{Phosphatidylinositol Extraction and Detection with Electroconductivity Method}

Phosphatidylinositol extraction for HPLC chromatography was performed using a one-step acidified Folch method. It is generally accepted that due to their negative charge, phosphorylated 
phosphatidylinositols remain tightly bound to proteins and cannot be extracted using standard lipid extraction procedures. However, protonation of phosphoinositides with the addition of hydrochloric acid $(\mathrm{HCl})$ neutralizes the negative charge on phosphoinositides, allowing their efficient extraction from proteins and partitioning from aqueous into organic phase during a standard Folch procedure. Flash-frozen retinas were homogenized in an ice-cold chloroform/methanol mixture (2C:1M supplemented with $0.1 \%$ of $\mathrm{HCl}$ ) in the presence of $200 \mu \mathrm{L}$ of acid-washed beads (G4649; Sigma) by bead beating (Mini-Bead-Beater-24, Biospec). Organic and aqueous phases were separated by the addition of $1 \mathrm{M} \mathrm{HCl}$ and centrifugation at $5000 \times \mathrm{g}$ for $5 \mathrm{~min}$ at $4{ }^{\circ} \mathrm{C}$. Lipids were collected from the lower organic phase, dried under a stream of nitrogen, and deacylated as described [20]. Briefly, the lipid pellet was resuspended in $200 \mu \mathrm{l}$ monomethylamine $(40 \%)$ : butanol: methanol: water (36:9:47:8), incubated in a Thermomixer (Eppendorf) at $53^{\circ} \mathrm{C}$ for $50 \mathrm{~min}$, chilled and dried in a SpeedVac (Eppendorf). The pellet was resuspended in $100 \mu \mathrm{L}$ water, and fatty acids were extracted twice with $100 \mu \mathrm{L}$ N-butanol: petroleum ether: ethyl formate (20:4:1). The aqueous phase containing headgroups of anionic phospholipids was dried in a SpeedVac, resuspended in $75 \mu \mathrm{L} \mathrm{H}_{2} \mathrm{O}$, and stored at $-20^{\circ} \mathrm{C}$.

Delipidated headgroups were separated on the Ionpac AS11-HC column (and AG11-HC guard column) connected to the ICS-2500 Dionex HPLC system. The column was equilibrated first with $10 \mathrm{mM} \mathrm{NaOH}$ and then with $1.5 \mathrm{mM} \mathrm{NaOH}$. After sample injection $(25 \mu \mathrm{L})$, elution was carried out in four stages at a flow rate of $0.38 \mathrm{~mL} / \mathrm{min}$ : (1) gradient from $1.5 \mathrm{mM}$ to $4 \mathrm{mM} \mathrm{NaOH}$ for $7 \mathrm{~min}$; (2) 4 to $16 \mathrm{mM} \mathrm{NaOH}$ for $5 \mathrm{~min}$; (3) 16 to $86 \mathrm{mM} \mathrm{NaOH}$ for $18 \mathrm{~min}$; (4) $15 \mathrm{~min}$ isocratic elution with $86 \mathrm{mM}$ $\mathrm{NaOH}$. Elution was monitored by suppressed conductivity detection with the ED50 electrochemical detector. Commercially available phosphorylated phosphatidylinositols (Avanti Polar Lipids) were used for phosphoinositide profiling after deacylation. For experiments requiring quantification and calibration, concentrations of $\mathrm{PI}(4) \mathrm{P}$ and $\mathrm{PI}(4,5) \mathrm{P}_{2}$ standards were measured by the colorimetric determination of phosphorus after digestion to inorganic phosphate and taking into consideration the number of phosphorus atoms in the corresponding lipid [21].

\subsection{Phosphatidylinositol Extraction and Detection with Mass Spectrometry}

In preliminary studies, we established that due to low abundance and ion suppression, phosphorylated phosphoinositides could not be detected with shotgun lipidomics in crude lipid extracts prepared by the one-step acidified Folch method described above. Therefore, we implemented a two-step procedure allowing preparation of retinal extract enriched for phosphorylated phosphatidylinositols, but significantly depleted of other phospholipids as described [22]. Extracted lipids were dried under a vacuum, resuspended in methanol supplemented with $0.1 \% \mathrm{HCl}$, infused into an LTQ orbitrap mass spectrometer (Thermo Scientific) with Triversa NanoMate (Advion), and analyzed in negative ion mode. Lipids were identified and quantified by LipidXplorer software [23]. Quantifications and calibrations were performed using lipidomics grade standards PI(4)P 17:0/20:4 and PI(4,5) $\mathrm{P}_{2}$ 17:0/20:4, (Avanti Polar Lipids), which are not present naturally in the mouse retina and have distinct and non-overlapping mass spectra compared to endogenous phosphoinositides. Phosphorylated phosphoinositides were extracted in the presence of standards containing approximately $1 / 5$ th of tissue homogenate of one mouse retina. Phosphatidylinositol profiling of retina was performed as described in [24]. The profiling of fatty acid composition of major mouse phosphatidylinositols (PI) was performed at Lipotype (Dresden, Germany). Phosphatidylinositol species were annotated using the total number of carbon atoms and the total number of double bonds in fatty acid moieties combined or individually. For example, phosphatidylinositol lipid containing 18:0 (stearic) and 20:4 (arachidonic) fatty acids was abbreviated as PI 38:4 and PI 18:0/20:4.

\subsection{Distribution of PI(4)P and PI(4,5) $P_{2}$ in Rod Photoreceptors}

Genes of interest were subcloned into a plasmid driving expression under the $2.2 \mathrm{~kb}$ bovine rhodopsin promoter [25]. Constructs included rhodopsin C-terminally tagged with mCherry, and Green Fluorescent Protein (GFP)-tagged phosphoinositide binding domains from phospholipase C $\delta 1$ (PLC $\delta 1$ ), 
Tubby, and four-phosphate-adaptor protein 1 (FAPP1) proteins as PI(4,5) $\mathrm{P}_{2}$ and PI(4)P sensors [26-29]. Constructs coding for sensors were delivered into photoreceptors by in vivo electroporation, as described in [25]. Briefly, neonatal mice (P0.5) were anesthetized on ice, and their sclera punctured through the eyelid with a 30-gauge needle at the six o'clock position. A solution containing $0.5 \mu \mathrm{L}$ of 5-6 $\mu$ g DNA mix was delivered subretinally with a blunt-end 32-gauge needle attached to a Hamilton Syringe. DNA solution contained vectors coding for rhodopsin-mCherry and phosphoinositide sensor in equal amounts. Electroporation was performed by delivering five $100 \mathrm{~V}$ pulses of $50 \mathrm{~ms}$ duration with ECM830 pulse generator (BTX, Harvard Apparatus) using tweezer electrodes covered with Gonak solution (Akorn) and positioned over the mouse eye. After electroporation, mice were returned to the cages and analyzed six weeks later. Three to five successfully electroporated animals were examined for each experimental condition.

\subsection{Statistical Analysis}

Statistical analysis, including linear regression fits, was carried out using Graph Pad PRISM 8. Data are expressed as means $+/$ - standard deviation. Moreover, $p$-values below $0.05(p<0.05)$ were considered statistically significant.

\section{Results}

\subsection{Retinal Composition of Major Phosphoinositide Headgroups}

To establish a profile of phosphorylated phosphoinositides in the mouse retina, we took advantage of a previously reported method allowing the separation of deacylated phosphoinositide headgroups by anion exchange high-pressure liquid chromatography (HPLC) and detection of eluted ions by suppressed conductivity [20]. A typical HPLC separation profile of delipidated headgroups obtained from mouse retina is shown in Figure 1a. The two peaks eluted at characteristic retention times of $\sim 27.5$ and $\sim 35$ min correspond to PI(4)P and PI $(4,5) \mathrm{P}_{2}$, respectively (Figure 1a, arrows). The identity of each peak was established by mixing deacylated retinal extracts from mouse and deacylated standards (Figure 1b). In the example shown in Figure 1b, supplementing the retinal extract with deacylated PI(3)P and PI(5)P resulted in the appearance of additional peaks, whereas the addition of PI(4)P increased the height of the original PIP peak, indicating that this peak represented PI(4)P. The same approach was used to establish the identity of the $\mathrm{PIP}_{2}$ peak as $\mathrm{PI}(4,5) \mathrm{P}_{2}$ (Figure 1c).

Next, using deacylated PI(4)P and PI(4,5) $\mathrm{P}_{2}$ standards, we established the linearity of this method in a range from 50 to $800 \mathrm{pmol}$ (Figure 1d). We noted that the slope for $\mathrm{PI}(4,5) \mathrm{P}_{2}$ is more shallow than for PI(4)P, so an identical amount of PI(4,5) $\mathrm{P}_{2}$ yields a smaller peak than PI(4)P. This is most likely due to a higher negative charge of $\mathrm{PI}(4,5) \mathrm{P}_{2}$, which requires higher concentrations of $\mathrm{NaOH}$ for elution and a higher extent of ion suppression for detection. In pilot studies, we found significant variability in the handling of phosphoinositides under 25 pmol; therefore, we aimed our subsequent measurements at around 100 pmol. The absolute amounts of PI(4)P and PI(4,5) $\mathrm{P}_{2}$ extracted from one mouse retina under optimized extraction and delipidation protocols approached $\sim 150 \mathrm{pmol}$ per retina (Figure 1e). This method requires substantial sample handling and does not allow consistent control of material loss during extraction and delipidation, limiting our ability to reliably assess potential light-dependent changes of the total pools of phosphoinositides. Therefore, we instead analyzed changes in the ratio of $\mathrm{PI}(4) \mathrm{P} / \mathrm{PI}(4,5) \mathrm{P}_{2}$ extracted from retinas of dark- and light-adapted mice (Figure 1f). These measurements did not reveal any statistically significant light-dependent phosphoinositide changes. 


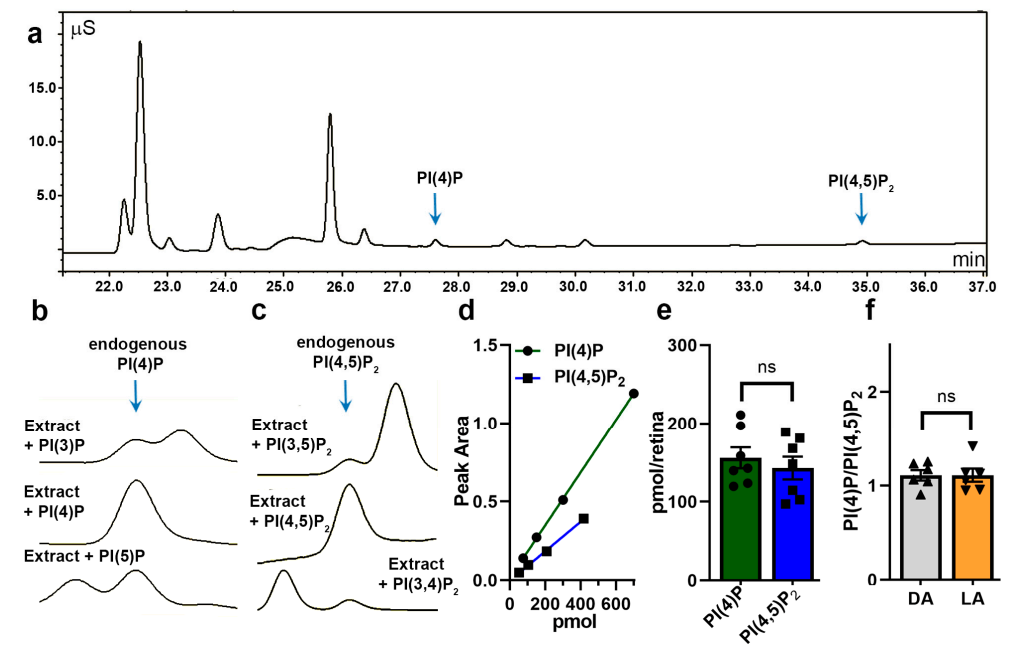

Figure 1. $\mathrm{PI}(4) \mathrm{P}$ and $\mathrm{PI}(4,5) \mathrm{P}_{2}$ are the major phosphorylated phosphoinositides in the mouse retina. (a) Representative chromatogram of headgroups from delipidated phosphoinositides extracted from the mouse retina, separated by anion-exchange HPLC and monitored by suppressed conductivity detection. $(\mathbf{b}, \mathbf{c})$ Chromatograms of delipidated headgroups obtained from mouse retinal extracts separated in the presence of different delipidated phosphorylated phosphoinositide standards. PI(4) (b) and $\mathrm{PI}(4,5) \mathrm{P}_{2}$ (c) are major phosphorylated inositide headgroups in the retina. (d) Calibration curves for headgroups from delipidated $\mathrm{PI}(4) \mathrm{P}$ and $\mathrm{PI}(4,5) \mathrm{P}_{2}$ standards are linear in the range 50-800 pmol ( $\mathrm{n}=3$; error bars are not plotted due to SD values being smaller than symbol sizes). (e) The retina contains comparable amounts of $\mathrm{PI}(4) \mathrm{P}$ and $\mathrm{PI}(4,5) \mathrm{P}_{2}(\sim 150$ pmol; $p=0.52)$. (f) The $\mathrm{PI}(4) \mathrm{P}$ to $\mathrm{PI}(4,5) \mathrm{P}_{2}$ ratio in the retina remains unchanged in dark-adapted (DA, gray) and light-adapted (LA, orange) mice $(p=0.98)$.

\subsection{Fatty Acid Composition of Major Retinal Phosphoinositides}

One limitation of the conductivity detection method is a loss of information about the fatty acid composition of $\mathrm{PI}(4) \mathrm{P}$ and $\mathrm{PI}(4,5) \mathrm{P}_{2}$ upon their delipidation. Therefore, we complemented phosphoinositide profiling with shotgun lipidomics and high-resolution mass spectrometry. This method allows the identification of lipid species by accurate mass measurements and the identification of the acyl composition of phospholipids by fragmentation.

In the first set of experiments, we looked at the fatty acid composition of retinal phosphatidylinositols, the precursors of phosphorylated phosphoinositides. The phosphatidylinositol profile was dominated by two species containing arachidonic acid: PI 18:0/20:4 (PI 38:4) and PI 16:0/20:4 (PI 36:4) (Figure 2a; see Figure 2b for illustrations of their structures). These accounted for $\sim 60 \%$ and $\sim 22 \%$ of the total retinal PI, respectively. Notably, we also detected trace amounts of PI species containing fatty acids with odd carbon numbers. It is generally accepted that mammals do not synthesize fatty acids with an odd number of carbons de novo. Therefore, these fatty acids are most likely obtained from a plant-based food diet [30,31]. 

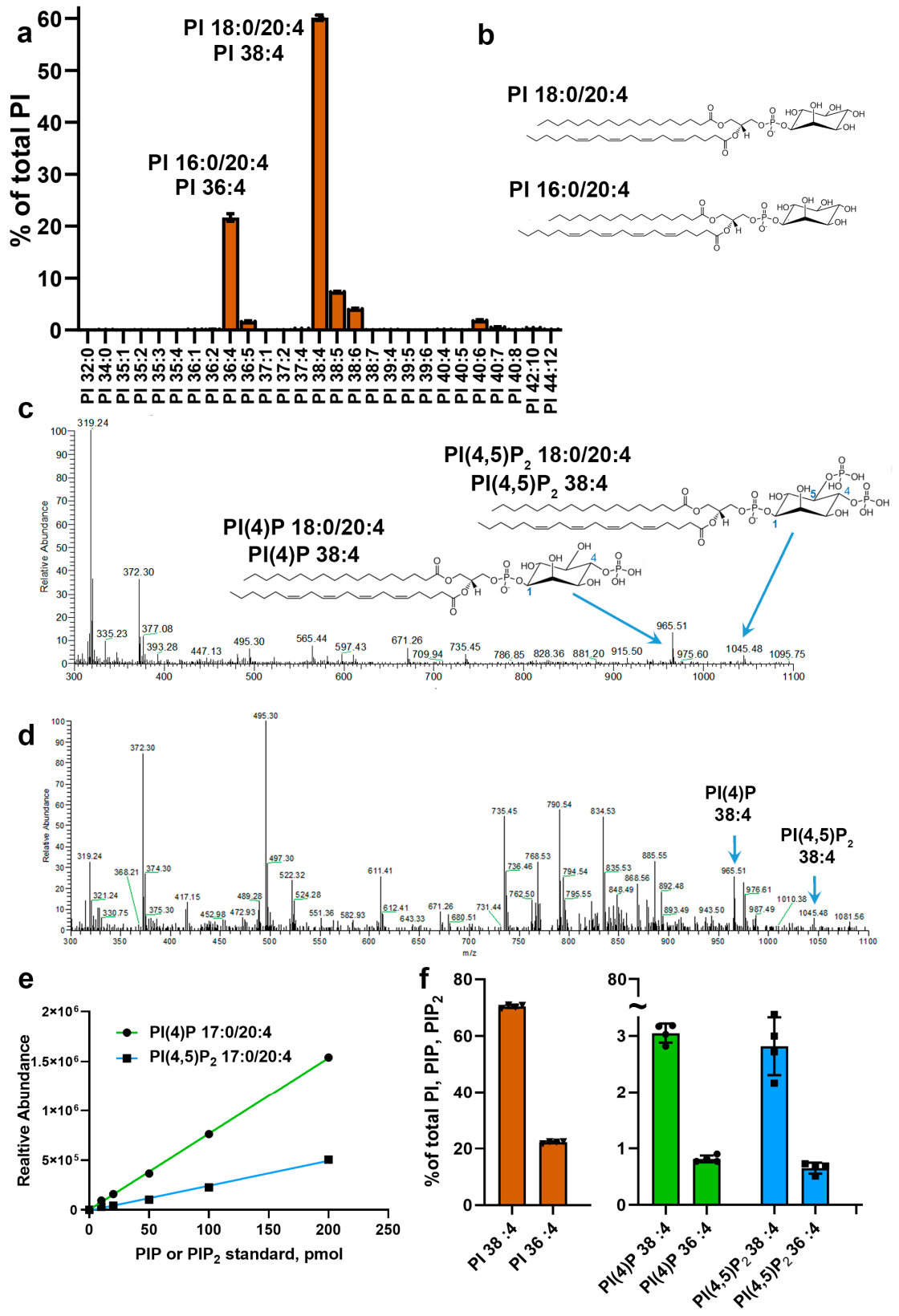

Figure 2. Lipidomic analysis of retinal phosphoinositides. (a) Lipid profiles of retinal phosphatidylinositols in 5-week-old wild type mice (mean+/-SD, $\mathrm{n}=3$ ). Phosphatidylinositols are shown as a percentage of the total. (b) Structures of major arachidonic acid-containing PI species, 16:0/20:4 and 18:0/20:4. (c) Mass spectra and structures of $\mathrm{PI}(4) \mathrm{P} 16: 0 / 20: 4$ and $\mathrm{PI}(4,5) \mathrm{P}_{2}$ 18:0/20:4 standards detected by direct infusion with high-resolution mass spectrometry as single ions in negative mode (blue arrows). (d) Representative mass spectra of lipids from mouse retinal extracts collected in negative ion mode. Peaks representing endogenous PI(4)P 38:4 and PI(4,5) $\mathrm{P}_{2}$ 38:4 are marked with blue arrows. (e) Calibration curves of $\mathrm{PI}(4) \mathrm{P}$ 17:0/20:4 and $\mathrm{PI}(4,5) \mathrm{P}_{2}$ 17:0/20:4 standards are linear in the 10 to 200 pmol range $(\mathrm{n}=3$; error bars are not plotted due to SD values being smaller than symbol sizes). (f) Lipid profiles of 36:4 and 38:4 phosphatidylinositols (PI, brown) and their phosphorylated forms (PI(4)P, green; $\mathrm{PI}(4,5) \mathrm{P}_{2}$, blue) in dark-adapted mouse retinas (mean+/-SD, $\mathrm{n}=4$ ). 
In control experiments employing phosphorylated forms of the predominant retinal phosphatidylinositols PI(4)P 18:0/20:4 (PIP 38:4) and PI(4,5) $\mathrm{P}_{2}$ 18:0/20:4 ( $\mathrm{PIP}_{2}$ 38:4) as standards, we confirmed that these species are detected as single ions in negative mode (Figure $2 \mathrm{c}$ ). This is consistent with previous lipidomic studies of phosphoinositides in other tissues [32]. Note that other peaks in Figure 2c represent a typical nonspecific spectral background and correspond to chemicals extracted from laboratory plastics exposed to organic solutions during sample preparation and infused into the mass spectrometer. In a separate set of experiments, we established an approach allowing us to detect the ions representing endogenous mono- and bisphosphate inositides in mouse retinal extracts (Figure 2d, marked with blue arrows). This analysis, combined with the results of the electroconductivity studies described above, suggests that these ions correspond to PI(4)P 38:4 and $\mathrm{PI}(4,5) \mathrm{P}_{2} 38: 4$. Next, using as standards phosphorylated phosphatidylinositols that are not naturally present in mammalian membranes (PI(4)P 37:4 and $\left.\mathrm{PI}(4,5) \mathrm{P}_{2} 37: 4\right)$, we established the linearity of this method and a detection limit as low as $10 \mathrm{pmol}$ (Figure 2e).

Our analysis of the phosphoinositide composition of the mouse retina is summarized in Figure $2 \mathrm{f}$. First, we established the dominant phosphorylated phosphatidylinositols as 38:4 and 36:4 acylated species. Second, we found that the retina contains comparable amounts of PI(4)P (green) and PI $(4,5) \mathrm{P}_{2}$ (blue), confirming the results of electroconductivity studies described above. Third, we estimated that phosphorylated inositides account for $\sim 7 \%$ of total phosphatidylinositols containing 38:4/36:4 acyls. Finally, we observed that the ratio of 38:4 to $36: 4$ acyl species is essentially unaffected by the status of inositol phosphorylation.

\subsection{Subcellular Distribution of PI(4,5)P $P_{2}$ and PI(4)P in Mouse Rod Photoreceptors}

In the final set of experiments, we investigated the localization of phosphoinositides in rod photoreceptors. This was accomplished by delivering constructs encoding GFP sensors of $\mathrm{PI}(4,5) \mathrm{P}_{2}$ and $\mathrm{PI}(4) \mathrm{P}$ into mouse rods by in vivo electroporation. Previous studies had reported light-dependent changes in the levels of these phosphoinositides [33] and their modulatory effects on the phototransduction cascade [34] and enzymatic activities (also reviewed in $[16,17,35,36]$ ). Therefore, we designed experiments allowing us to assess the presence of phosphoinositides in different subcellular compartments of the rod cells, particularly the light-sensitive outer segment. To this end, DNA constructs encoding the phosphoinositide sensors were electroporated together with fluorescently tagged rhodopsin, a resident protein of outer segments.

The most commonly used sensor of PI(4,5) $\mathrm{P}_{2}$, PLC 81 PH-GFP, was found mostly outside ofouter segments, with an intense labeling of the inner segments and synapses (Figure 3a). Localization of this sensor in rods of light- and dark-adapted retinas had a similar pattern. The same localization pattern was observed for TubbyPH-GFP, an alternative specific sensor of $\mathrm{PI}(4,5) \mathrm{P}_{2}$ (Figure $3 b$ ). In contrast, the FAPP1PH-GFP sensor of PI(4)P (Figure 3c) was present in the outer segments, as illustrated by its overlapping localization with mCherry-tagged rhodopsin. We also observed a sizable fraction of PI(4)P sensor in the inner segments and in an area around the nuclei. Overall, there was no definitive change in the localization patterns of the PI(4)P sensor in dark- and light-adapted mice. The localization pattern of the sensors in relation to the outer segments was consistent with a previous analysis, which documented the presence of $\mathrm{PI}(4) \mathrm{P}$ but not $\mathrm{PI}(4,5) \mathrm{P}_{2}$ in preparations of bovine outer segments [20]. 
PLCס1PH-GFP

a Rhodopsin-mCherry

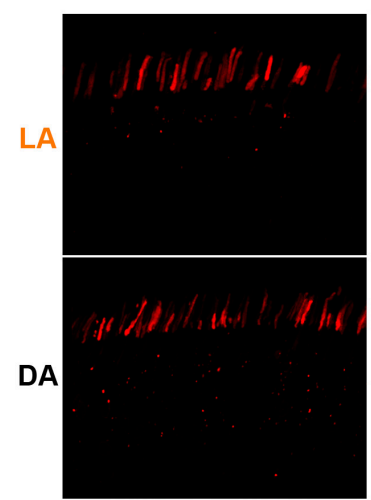

TubbyPH-GFP

b Rhodopsin-mCherry

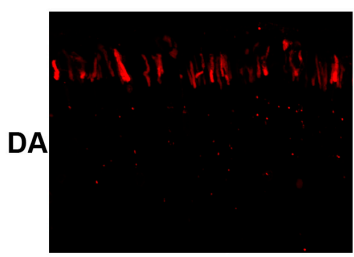

FAPP1PH-GFP

C Rhodopsin-mCherry

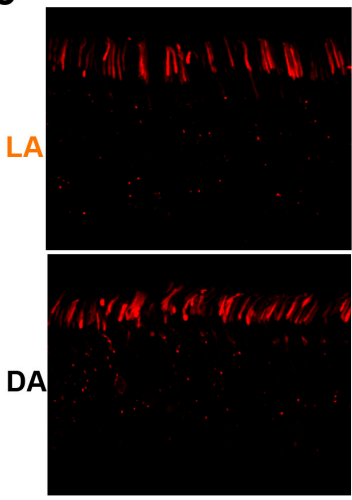

$\mathrm{PI}(4,5) \mathrm{P}_{2}$

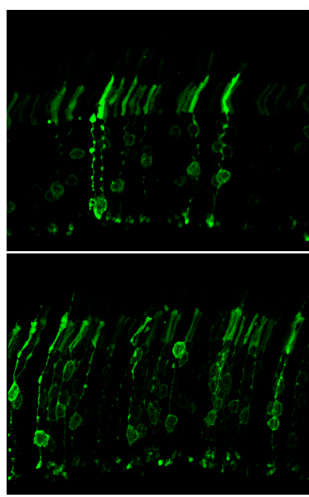

$\mathrm{PI}(4,5) \mathrm{P}_{2}$

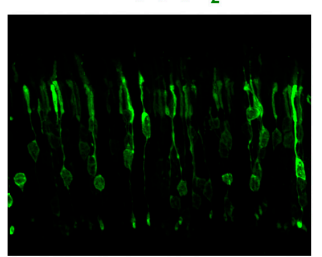

PI(4)P

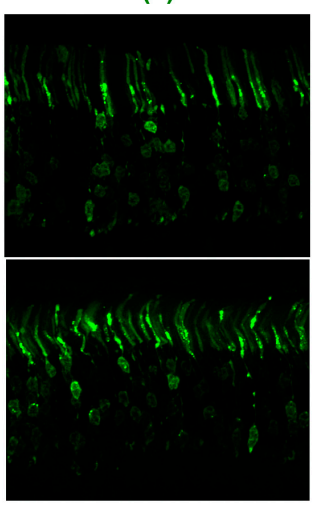

Rhodopsin-mCherry $\mathrm{Pl}(4,5) \mathrm{P}_{2}$

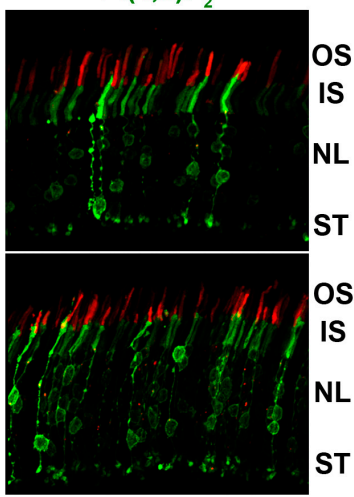

Rhodopsin-mCherry $\mathrm{PI}(4,5) \mathrm{P}$

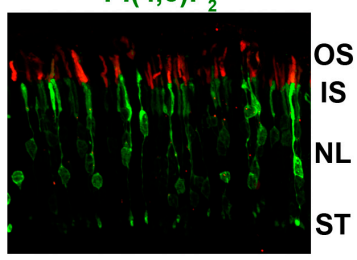

Rhodopsin-mCherry PI(4)P

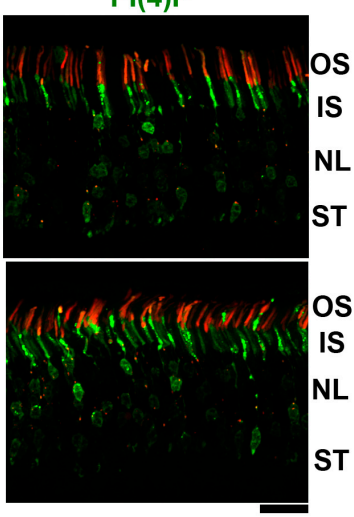

Figure 3. Distribution of $\mathrm{PI}(4) \mathrm{P}$ and $\mathrm{PI}(4,5) \mathrm{P}_{2}$ phosphoinositide sensors in rod photoreceptors. Green Fluorescent Protein (GFP) fusion constructs of PI(4,5) $\mathrm{P}_{2}$-binding domains from PLC $\delta 1$ (a) and Tubby (b) proteins and the PI(4)P-binding domain of FAPP1 (c) were electroporated at P0 into rod photoreceptors to investigate the localization of corresponding phosphoinositides. Their distribution patterns (green) were analyzed in retinal cross-sections of 6-week-old dark (DA)- or light (LA)- adapted mice. Rhodopsin fused with mCherry (red) was used as a rod outer segment marker. $\mathrm{PI}(4,5) \mathrm{P}_{2}$ sensors produce intense signals in the inner segments (IS), nuclear layer (NL) and synaptic terminals (ST), but are virtually excluded from outer segments (OS). The PI(4)P sensor shows signal in the outer segments, around nuclei, and in the inner segments. Occasional red puncta detected in the inner segments most likely represent mistargeted Rhodopsin-mCherry fusion protein. Scale bar: $20 \mu \mathrm{m}$.

\section{Discussion}

Studies conducted over the past decade have highlighted the complexity of cellular processes controlled by phosphorylated forms of phosphoinositides, including cytoskeleton organization, channel modulation, endosomal and lysosomal transport, protein trafficking, cell polarization, and gene expression. However, the functional significance of phosphoinositide metabolism in the retina is poorly understood, and the phosphoinositide composition of this tissue has remained uncharacterized. Traditionally used radiolabeling techniques may assess turnover of lipids and 
changes in enzymatic activities but do not allow measurement of the absolute levels of individual phosphoinositides. Until recently, progress in this direction was hindered by a lack of sensitive techniques suitable for phosphoinositide quantification without lipid radiolabeling. In this study, we used modern non-radioactive analytical methods to characterize the composition of phosphorylated phosphatidylinositols in the mouse retina.

Using chromatography of delipidated phosphoinositide headgroups, we have established $\mathrm{P}(4,5) \mathrm{P}_{2}$ and $\mathrm{P}(4) \mathrm{P}$ as the major phosphorylated phosphatidylinositols in the mouse retina. The levels of $\mathrm{PI}(4,5) \mathrm{P}_{2}$ and $\mathrm{PI}(4) \mathrm{P}$ are comparable, and a mouse retina contains approximately 150 pmol of each lipid. This number most likely represents a low-end estimate due to less than $100 \%$ efficiency of lipid extraction from the tissue.

Several reports suggest that light regulates the levels of $\mathrm{PI}(4) \mathrm{P}$ and $\mathrm{PI}(4,5) \mathrm{P}_{2}$ in rod outer segments (reviewed in [16]). However, the biological function of this regulation remains unknown, and even the direction of the light-induced phosphoinositide changes was not consistent across these studies. Early studies with radioactive labeling suggested that the $\mathrm{PI}(4,5) \mathrm{P}_{2}$ level in whole retinas is reduced by light [37] and implicated the activation of phospholipase C [38]. In contrast, another study from the same laboratory detected light-stimulated synthesis of $\mathrm{PI}(4) \mathrm{P}$ and $\mathrm{PI}(4,5) \mathrm{P}_{2}$ in isolated rod outer segments in vitro [39]. Unfortunately, the electroconductivity method we utilized requires extensive sample handling, which does not allow control of material loss during extraction and delipidation, limiting our ability to reliably assess potential light-dependent changes of the total pools of phosphoinositides in different samples. Therefore, we instead compared ratios of $\mathrm{PI}(4) \mathrm{P} / \mathrm{PI}(4,5) \mathrm{P}_{2}$ extracted from retinas of the dark- and light-adapted mice. This analysis did not reveal statistically significant changes, indicating either that both lipids change proportionally or that they do not change at all. However, we cannot exclude the possibility that analyzing whole retina extracts might mask small changes in the profiles of these lipids within individual subcellular compartments and/or subsets of retinal cells.

The contents of other phosphoinositides, $\mathrm{PI}(3) \mathrm{P}, \mathrm{PI}(5) \mathrm{P}, \mathrm{PI}(3,4) \mathrm{P}_{2}, \mathrm{PI}(3,5) \mathrm{P}_{2}, \mathrm{PI}(3,4,5) \mathrm{P}_{3}$, were below our detection limit, indicating that their retinal content lies somewhere below single picomolar levels. Although they were not detected here, they are most likely present in the retina and may play significant roles in retinal health. Consistent with this notion, inactivation of enzymes handling PI(3)P was reported to result in defects in mouse photoreceptors and bipolar cells [7,8,40]. Future development and validation of sensitive analytical methods allowing measurement of phosphorylated phosphoinositides at femtomolar levels, similar to the recently reported ELISA-based approach [7], will be necessary to accurately quantify these less abundant species.

Using mass spectrometry-based lipidomics, we found that at least $82 \%$ of the total phosphatidylinositide pool in the mouse retina is represented by arachidonic acid-containing species, PI 38:4, and PI 36:4. The same acyl composition was identified for mono- and bisphosphate phosphorylated forms (PIP 36:4/38:4 and $\mathrm{PIP}_{2} 36: 4 / 38: 4$ ), which account for 7\% of total retinal phosphatidylinositol. The predominance of arachidonic acid-containing PI(4)P and $\mathrm{PI}(4,5) \mathrm{P}_{2}$ species is largely consistent with phosphoinositide profiles of mammalian membranes and neuronal tissues [41,42]. However, the biological significance of selective enrichment of phosphatidylinositols with arachidonic acid remains unknown [43].

Finally, we used genetic phosphoinositide sensors to infer the subcellular location of $\mathrm{PI}(4,5) \mathrm{P}_{2}$ and PI(4)P within rod photoreceptors. The main difference in the subcellular distribution of these phosphoinositide species is that $\mathrm{PI}(4) \mathrm{P}$ was present in the light-sensitive outer segment, whereas $\mathrm{PI}(4,5) \mathrm{P}_{2}$ was mostly excluded from this compartment. This observation is consistent with a previous study, which reported the presence of $\mathrm{PI}(4) \mathrm{P}$ but not $\mathrm{PI}(4,5) \mathrm{P}_{2}$ in membranes of bovine outer segments [20]. We also noted significant enrichment of the PI $(4,5) \mathrm{P}_{2}$ sensor but not the PI(4)P sensor in photoreceptor synapses. The latter is consistent with zebrafish studies demonstrating the critical role of SynJ1 (a phosphatase regulating the levels of 5-phosphate-containing phosphoinositides) in the synapses of photoreceptors [5,6]. Admittedly, any interpretation of phosphoinositide distributions based on localization patterns of sensors should be conservative, due to the inherent limitations of 
a protein overexpression approach [44,45]. Sensor overexpression could disrupt the distribution of endogenous phosphoinositides and phosphoinositide-binding proteins and is subject to variability among individual photoreceptors and injection procedures. Nevertheless, the stark dissimilarity in the sensors' distributions is encouraging and supports the notion of distinct subcellular localization patterns of PI(4)P and PI(4,5) $\mathrm{P}_{2}$ in rods. Notably, our overexpression experiments did not reveal dramatic rearrangements of sensors under dark/light conditions. However, we cannot exclude the possibility that this approach is not sensitive enough to detect small light-dependent rearrangements. The development of stable transgenic mice expressing sensors at controlled levels and recent advances in high-resolution microscopy will permit a more rigorous assessment of the role of $\mathrm{PI}(4) \mathrm{P}$ and $\mathrm{PI}(4,5) \mathrm{P}_{2}$ as key players in inositide signaling in the retina.

\section{Conclusions}

Phosphatidylinositol can be phosphorylated combinatorially on three positions, producing seven distinct forms of phosphoinositides. Our study establishes $\mathrm{PI}(4) \mathrm{P}$ and $\mathrm{PI}(4,5) \mathrm{P}_{2}$ as predominant phosphoinositide species in the mouse retina and describes subcellular distribution patterns of these lipids in rod photoreceptors. Combined with reports linking mutations in enzymes controlling levels of phosphoinositides phosphorylated at the fifth position with retinal disorders in humans $[9,10,46]$, these findings encourage further mechanistic studies to define precise functional roles of $\mathrm{PI}(4) \mathrm{P}$ and $\mathrm{PI}(4,5) \mathrm{P}_{2}$ lipids in the retina.

The goal of future studies is to establish which phosphoinositide kinases and phosphatases are critical for maintaining the levels of $\mathrm{PI}(4) \mathrm{P}$ and $\mathrm{PI}(4,5) \mathrm{P}_{2}$ in this tissue and, most importantly in photoreceptors. It would also be interesting to use nonradioactive methods of phosphoinositide detection to compare the phosphoinositide composition of mouse and human retinas. Another future goal is to address whether pathological changes in the levels and distribution of phosphoinositides contribute to blindness in diseases that are not directly caused by disruptions of phosphoinositide metabolism, such as retinitis pigmentosa or syndromic ciliopathies [47-52].

Author Contributions: Conceptualization, A.S., V.Y.A. and E.S.L.; Formal analysis, E.S.L.; Investigation, S.F., S.M.G.III, K.S., and E.S.L.; Writing—original draft, E.S.L.; Writing—review \& editing, S.F., S.M.G., K.S., A.S., V.Y.A., and E.S.L. All authors have read and agreed to the published version of the manuscript.

Funding: This work was supported by National Institutes of Health Grants EY030043 (E.S.L.), EY028610 (S.M.G.), EY005722 (V.Y.A.), EY010336 (V.Y.A.), EY012859 (V.Y.A.); The University of Florida startup funds (E.S.L.); unrestricted Grants from Research to Prevent Blindness to the Departments of Ophthalmology of University of Florida and Duke University; the German Research Foundation TRR83 Grant project A17; Federal Ministry of Education and Research LIFS Grant.

Conflicts of Interest: The authors state that they have no competing financial interests. The funders had no role in study design, data collection, and analysis, decision to publish, or preparation of the manuscript.

$\begin{array}{ll}\text { Abbreviations } \\ \text { C } & \text { chloroform } \\ \text { DA } & \text { dark-adapted } \\ \text { FAPP1 } & \text { four-phosphate-adaptor protein } 1 \\ \text { GFP } & \text { green fluorescent protein } \\ \text { HCl } & \text { hydrochloric acid } \\ \text { HPLC } & \text { high-performance liquid chromatography } \\ \text { INPP5E } & \text { inositol polyphosphate-5-phosphatase E } \\ \text { LA } & \text { light-adapted } \\ \text { M } & \text { methanol } \\ \text { NaOH } & \text { sodium hydroxide } \\ \text { PBS } & \text { phosphate-buffered saline } \\ \text { PH } & \text { pleckstrin homology domain } \\ \text { PI } & \text { phosphatidylinositol } \\ \text { PI(4)P } & \text { phosphatidylinositol 4-monophosphate }\end{array}$


$\mathrm{PI}(4,5) \mathrm{P}_{2}$ phosphatidylinositol 4,5-bisphosphate

PI3K phosphoinositide 3-kinase

PLC $\delta$ phospholipase $\mathrm{C} \delta$

ROS rod outer segments

SynJ1 synaptojanin 1

Vps34 vacuolar protein sorting 34

\section{References}

1. de Craene, J.-O.; Bertazzi, D.L.; Bar, S.; Friant, S. Phosphoinositides, Major Actors in Membrane Trafficking and Lipid Signaling Pathways. Int. J. Mol. Sci. 2017, 18, 634. [CrossRef] [PubMed]

2. Schink, K.O.; Tan, K.-W.; Stenmark, H. Phosphoinositides in Control of Membrane Dynamics. Annu. Rev. Cell Dev. Boil. 2016, 32, 143-171. [CrossRef] [PubMed]

3. Balla, T. Phosphoinositides: Tiny lipids with giant impact on cell regulation. Physiol. Rev. 2013, 93, 1019-1137. [CrossRef] [PubMed]

4. Hammond, G.R.; Burke, J.E. Novel roles of phosphoinositides in signaling, lipid transport, and disease. Curr. Opin. Cell Boil. 2020, 63, 57-67. [CrossRef] [PubMed]

5. George, A.A.; Hayden, S.; Holzhausen, L.C.; Ma, E.Y.; Suzuki, S.C.; Brockerhoff, S.E. Synaptojanin 1 Is Required for Endolysosomal Trafficking of Synaptic Proteins in Cone Photoreceptor Inner Segments. PLOS ONE 2014, 9, e84394. [CrossRef]

6. George, A.A.; Hayden, S.; Stanton, G.R.; Brockerhoff, S.E. Arf6 and the 5'phosphatase of synaptojanin 1 regulate autophagy in cone photoreceptors. Bioessays 2016, 38, 119-135. [CrossRef]

7. He, F.; Agosto, M.; Anastassov, I.; Tse, D.Y.; Wu, S.M.; Wensel, T.G. Phosphatidylinositol-3-phosphate is light-regulated and essential for survival in retinal rods. Sci. Rep. 2016, 6, 26978. [CrossRef]

8. Rajala, R.V.S.; Ranjo-Bishop, M.; Wang, Y.; Rajala, A.; Anderson, R.E. The $\mathrm{p} 110 \alpha$ isoform of phosphoinositide 3-kinase is essential for cone photoreceptor survival. Biochimie 2015, 112, 35-40. [CrossRef]

9. Brooks, B.P.; Zein, W.M.; Thompson, A.; Mokhtarzadeh, M.; Doherty, D.; Parisi, M.; Glass, I.A.; Malicdan, M.C.; Vilboux, T.; Vemulapalli, M.; et al. Joubert Syndrome: Ophthalmological Findings in Correlation with Genotype and Hepatorenal Disease in 99 Patients Prospectively Evaluated at a Single Center. Ophthalmology 2018, 125, 1937-1952. [CrossRef]

10. Travaglini, L.; Brancati, F.; Silhavy, J.; Iannicelli, M.; Nickerson, E.; Elkhartoufi, N.; Scott, E.; Spencer, E.; Gabriel, S.; Thomas, S.; et al. Phenotypic spectrum and prevalence of INPP5E mutations in Joubert Syndrome and related disorders. Eur. J. Hum. Genet. 2013, 21, 1074-1078. [CrossRef]

11. Hagstrom, S.A.; Duyao, M.; North, M.A.; Li, T. Retinal degeneration in tulp1-/- mice: Vesicular accumulation in the interphotoreceptor matrix. Investig. Ophthalmol. Vis. Sci. 1999, 40, 2795-2802.

12. Hagstrom, S.A.; North, M.A.; Nishina, P.M.; Berson, E.L.; Dryja, T.P. Recessive mutations in the gene encoding the tubby-like protein TULP1 in patients with Retinitis pigmentosa. Nat. Genet. 1998, 18, 174-176. [CrossRef] [PubMed]

13. Ikeda, A.; Naggert, J.K.; Nishina, P.M. Genetic Modification of Retinal Degeneration in Tubby Mice. Exp. Eye Res. 2002, 74, 455-461. [CrossRef] [PubMed]

14. Chuang, J.-Z.; Zhao, Y.; Sung, C.-H. SARA-regulated vesicular targeting underlies formation of the light-sensing organelle in mammalian rods. Cell 2007, 130, 535-547. [CrossRef] [PubMed]

15. Deretic, D.; Traverso, V.; Parkins, N.; Jackson, F.; de Turco, E.B.R.; Ransom, N. Phosphoinositides, Ezrin/Moesin, and rac1 Regulate Fusion of Rhodopsin Transport Carriers in Retinal Photoreceptors. Mol. Boil. Cell 2004, 15, 359-370. [CrossRef] [PubMed]

16. Giusto, N.; Pasquaré, S.J.; A Salvador, G.; I Castagnet, P.; E Roque, M.; De Boschero, M.G.I. Lipid metabolism in vertebrate retinal rod outer segments. Prog. Lipid Res. 2000, 39, 315-391. [CrossRef]

17. Wensel, T.G. Phosphoinositides in Retinal Function and Disease. Cells 2020, 9, 866. [CrossRef]

18. Lobanova, E.S.; Finkelstein, S.; Li, J.; Travis, A.M.; Hao, Y.; Klingeborn, M.; Skiba, N.P.; Deshaies, R.J.; Arshavsky, V.Y. Increased proteasomal activity supports photoreceptor survival in inherited retinal degeneration. Nat. Commun. 2018, 9, 1738. [CrossRef] 
19. Lobanova, E.S.; Herrmann, R.; Finkelstein, S.; Reidel, B.; Skiba, N.P.; Deng, W.-T.; Jo, R.; Weiss, E.R.; Hauswirth, W.; Arshavsky, V.Y. Mechanistic basis for the failure of cone transducin to translocate: Why cones are never blinded by light. J. Neurosci. 2010, 30, 6815-6824. [CrossRef]

20. Nasuhoglu, C.; Feng, S.; Mao, J.; Yamamoto, M.; Yin, H.L.; Earnest, S.; Barylko, B.; Albanesi, J.P.; Hilgemann, D.W. Nonradioactive Analysis of Phosphatidylinositides and Other Anionic Phospholipids by Anion-Exchange High-Performance Liquid Chromatography with Suppressed Conductivity Detection. Anal. Biochem. 2002, 301, 243-254. [CrossRef]

21. Rouser, G.; Fkeischer, S.; Yamamoto, A. Two dimensional then layer chromatographic separation of polar lipids and determination of phospholipids by phosphorus analysis of spots. Lipids 1970, 5, 494-496. [CrossRef] [PubMed]

22. Milne, S.B.; Ivanova, P.T.; de Camp, D.; Hsueh, R.C.; Brown, H.A. A targeted mass spectrometric analysis of phosphatidylinositol phosphate species. J. Lipid Res. 2005, 46, 1796-1802. [CrossRef] [PubMed]

23. Herzog, R.; Schwudke, D.; Schuhmann, K.; Sampaio, J.; Bornstein, S.; Schroeder, M.; Shevchenko, A. A novel informatics concept for high-throughput shotgun lipidomics based on the molecular fragmentation query language. Genome Boil. 2011, 12, R8. [CrossRef] [PubMed]

24. Lobanova, E.S.; Schuhmann, K.; Finkelstein, S.; Lewis, T.; Cady, M.A.; Hao, Y.; Keuthan, C.; Ash, J.D.; Burns, M.E.; Shevchenko, A.; et al. Disrupted Blood-Retina Lysophosphatidylcholine Transport Impairs Photoreceptor Health But Not Visual Signal Transduction. J. Neurosci. 2019, 39, 9689-9701. [CrossRef] [PubMed]

25. Matsuda, T.; Cepko, C.L. Electroporation and RNA interference in the rodent retina in vivo and in vitro. Proc. Natl. Acad. Sci. USA 2003, 101, 16-22. [CrossRef]

26. Balla, T.; Tuymetova, G.; Tsiomenko, A.; Várnai, P.; Balla, T. A Plasma Membrane Pool of Phosphatidylinositol 4-Phosphate Is Generated by Phosphatidylinositol 4-Kinase Type-III Alpha: Studies with the PH Domains of the Oxysterol Binding Protein and FAPP1. Mol. Boil. Cell 2005, 16, 1282-1295. [CrossRef] [PubMed]

27. Hammond, G.R.; Fischer, M.J.; Anderson, K.E.; Holdich, J.; Koteci, A.; Balla, T.; Irvine, R.F. PI4P and PI $(4,5)$ P2 Are Essential but Independent Lipid Determinants of Membrane Identity. Science 2012, 337, 727-730. [CrossRef]

28. Szentpetery, Z.; Balla, T.; Kim, Y.J.; Lemmon, M.A.; Balla, T. Live cell imaging with protein domains capable of recognizing phosphatidylinositol 4,5-bisphosphate; A comparative study. BMC Cell Boil. 2009, 10, 67. [CrossRef]

29. Balla, T.; Várnai, P. Visualization of Cellular Phosphoinositide Pools with GFP-Fused Protein-Domains. Curr. Protoc. Cell Boil. 2009, 42. [CrossRef]

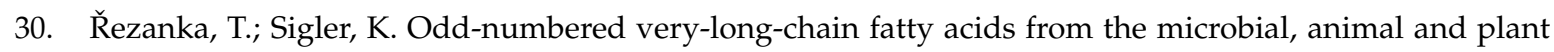
kingdoms. Prog. Lipid Res. 2009, 48, 206-238. [CrossRef]

31. Zhang, L.-S.; Liang, S.; Zong, M.-H.; Yang, J.-G.; Lou, W.-Y. Microbial synthesis of functional odd-chain fatty acids: A review. World J. Microbiol. Biotechnol. 2020, 36, 35-39. [CrossRef] [PubMed]

32. Wenk, M.R.; Lucast, L.; di Paolo, G.; Romanelli, A.J.; Suchy, S.F.; Nussbaum, R.L.; Cline, G.W.; Shulman, G.I.; McMurray, W.; de Camilli, P. Phosphoinositide profiling in complex lipid mixtures using electrospray ionization mass spectrometry. Nat. Biotechnol. 2003, 21, 813-817. [CrossRef] [PubMed]

33. Rajala, R.V.S.; Rajala, A.; Morris, A.J.; Anderson, R.E. Phosphoinositides: Minor Lipids Make a Major Impact on Photoreceptor Cell Functions. Sci. Rep. 2014, 4, 5463. [CrossRef] [PubMed]

34. He, F.; Mao, M.; Wensel, T.G. Enhancement of Phototransduction G Protein-Effector Interactions by Phosphoinositides. J. Boil. Chem. 2003, 279, 8986-8990. [CrossRef] [PubMed]

35. Rajala, R.V.S.; Anderson, R.E. Focus on Molecules: Phosphatidylinositol-4,5-bisphosphate (PIP2). Exp. Eye Res. 2010, 91, 324-325. [CrossRef]

36. Brockerhoff, E.S. Phosphoinositides and photoreceptors. Mol. Neurobiol. 2011, 44, 420-425. [CrossRef] [PubMed]

37. Ghalayini, A.; Anderson, R.E. Phosphatidylinositol 4,5-bisphosphate: Light-mediated breakdown in the vertebrate retina. Biochem. Biophys. Res. Commun. 1984, 124, 503-506. [CrossRef]

38. Ghalayini, A.J.; Weber, N.R.; Rundle, D.R.; A Koutz, C.; Lambert, D.; Guo, X.X.; E Anderson, R. Phospholipase Cgamma1 in bovine rod outer segments: Immunolocalization and light-dependent binding to membranes. J. Neurochem. 1998, 70, 171-178. [CrossRef] 
39. Ghalayini, A.J.; Anderson, R.E. Light adaptation of bovine retinas in situ stimulates phosphatidylinositol synthesis in rod outer segments in vitro. Curr. Eye Res. 1995, 14, 1025-1029. [CrossRef]

40. He, F.; Nichols, R.M.; Kailasam, L.; Wensel, T.G.; Agosto, M.A. Critical Role for Phosphatidylinositol-3 Kinase Vps34/PIK3C3 in ON-Bipolar Cells. Invest Ophthalmol. Vis. Sci. 2019, 60, 2861-2874. [CrossRef]

41. Raghu, P.; Joseph, A.; Krishnan, H.; Singh, P.; Saha, S. Phosphoinositides: Regulators of Nervous System Function in Health and Disease. Front. Mol. Neurosci. 2019, 12, 208. [CrossRef] [PubMed]

42. Waugh, M.G. PIPs in neurological diseases. Biochim. Biophys. Acta Mol. Cell Boil. Lipids 2015, 1851, 1066-1082. [CrossRef] [PubMed]

43. Barneda, D.; Cosulich, S.; Stephens, L.; Hawkins, P. How is the acyl chain composition of phosphoinositides created and does it matter? Biochem. Soc. Trans. 2019, 47, 1291-1305. [CrossRef] [PubMed]

44. Tsuji, T.; Takatori, S.; Fujimoto, T. Definition of phosphoinositide distribution in the nanoscale. Curr. Opin. Cell Boil. 2019, 57, 33-39. [CrossRef] [PubMed]

45. Wakelam, M. The uses and limitations of the analysis of cellular phosphoinositides by lipidomic and imaging methodologies. Biochim. Biophys. Acta Mol. Cell Boil. Lipids 2014, 1841, 1102-1107. [CrossRef] [PubMed]

46. Mehta, Z.B.; Piętka, G.; Lowe, M. The Cellular and Physiological Functions of the Lowe Syndrome Protein OCRL1. Traffic 2014, 15, 471-487. [CrossRef]

47. Bujakowska, K.M.; Liu, Q.; A Pierce, E. Photoreceptor Cilia and Retinal Ciliopathies. Cold Spring Harb. Perspect. Boil. 2017, 9, a028274. [CrossRef]

48. Verbakel, S.K.; van Huet, R.A.; Boon, C.J.; Hollander, A.I.D.; Collin, R.W.; Klaver, C.C.W.; Hoyng, C.; Roepman, R.; Klevering, B.J. Non-syndromic retinitis pigmentosa. Prog. Retin. Eye Res. 2018, 66, 157-186. [CrossRef]

49. Daiger, S.P.; Sullivan, L.S.; Bowne, S.J. Genes and mutations causing retinitis pigmentosa. Clin. Genet. 2013, 84, 132-141. [CrossRef]

50. Daiger, S.P.; Bowne, S.J.; Sullivan, L.S. Genes and Mutations Causing Autosomal Dominant Retinitis Pigmentosa. Cold Spring Harb. Perspect Med. 2014, 5. [CrossRef]

51. di Carlo, J.E.; Mahajan, V.B.; Tsang, S.H. Gene therapy and genome surgery in the retina. J. Clin. Investig. 2018, 128, 2177-2188. [CrossRef] [PubMed]

52. Baehr, W.; Hanke-Gogokhia, C.; Sharif, A.; Reed, M.; Dahl, T.; Frederick, J.M.; Ying, G. Insights into photoreceptor ciliogenesis revealed by animal models. Prog. Retin. Eye Res. 2018, 71, 26-56. [CrossRef] [PubMed]

(C) 2020 by the authors. Licensee MDPI, Basel, Switzerland. This article is an open access article distributed under the terms and conditions of the Creative Commons Attribution (CC BY) license (http://creativecommons.org/licenses/by/4.0/). 